1 Universidade Federal de São Paulo (Unifesp), campus Baixada Santista, Departamento de Políticas Públicas e Saúde Coletiva Santos (SP), Brasil. rosilda.mendes3@gmail.com

2 Universidade Federa de São Paulo (Unifesp), campus Baixada Santista, Departamento de Gestão e Cuidados em Saúde - Santos (SP), Brasil.

fernanda.frutuoso@unifesp.br

3 Universidade Federal de São Paulo (Unifesp), campus Baixada Santista, Departamento de Políticas Públicas e Saúde Coletiva - Santos (SP), Brasil. carobert3@hotmail.com

\section{Integralidade como processo intersubjetivo de construção de práticas em território de exclusão social}

\author{
Integrality as an intersubjective process of construction practices in a \\ territory of social exclusion
}

Rosilda Mendes ${ }^{\mathbf{1}}$, Maria Fernanda Petroli Frutuoso ${ }^{\mathbf{2}}$, Carlos Roberto de Castro e Silva ${ }^{\mathbf{3}}$

RESUMO Para discutir a integralidade como processo intersubjetivo de construção dos diálogos e das negociações produzidas no cotidiano dos profissionais que buscam responder ao sofrimento gerado por condições sociais de exclusão, foi realizado um estudo a partir de entrevistas com profissionais de uma Unidade de Saúde da Família de Cubatão (SP). Os relatos apontaram discursos e ações que valorizam os vínculos intersubjetivos e os afetos, que podem ser transformadores se articulados com a dimensão política. Manifestam-se desejos e interesses de sujeitos e instituições e revelam-se esforços empreendidos, apesar da precariedade no estabelecimento de políticas públicas em territórios marcados pela exclusão.

PALAVRAS-CHAVE Integralidade em saúde. Estratégia Saúde da Família. Vulnerabilidade social. Agentes Comunitários de Saúde.

ABSTRACT In order to discuss integrality as an intersubjective process for the construction of dialogues and negotiations produced in the daily life of professionals who seek to respond to the suffering generated by social conditions of exclusion, a study was conducted from interviews with professionals of a Family Health Unit in Cubatão (SP). The reports pointed out discourses and actions that valorize the intersubjective bonds and the affections, that can be transformative if articulated with the political dimension. Desires and interests of individuals and institutions are manifested and the efforts made are revealed, despite the precariousness in the establishment of public policies in territories marked by exclusion.

KEYWORDS Integrality in health. Family Health Strategy. Social vulnerability. Community Health Workers. 


\section{Introdução}

A finalidade deste artigo é analisar a integralidade como processo intersubjetivo de construção dos diálogos e das negociações produzidos no cotidiano dos profissionais que buscam responder ao sofrimento gerado por condições sociais de exclusão, que são, por isso, injustas. Na perspectiva de oferecer respostas mais abrangentes, mais articuladoras e mais adequadas ao cuidado integral e às necessidades e demandas de saúde, visa, também, salientar certo modo de pensar e operar a integralidade problematizando as práticas de saúde que requerem conexões, mediações, colaborações e pactuações.

Vários autores apontam que não existe uma única forma de compreender a integralidade e reforçam o caráter polissêmico do termo. Seus múltiplos sentidos podem ser complementares e inter-relacionados e, da perspectiva da produção social da saúde, adquirem importância estratégica. Dessa forma, o desafio é tomar a integralidade em todas as suas dimensões (AYRES, 2009A; AYRES ET AL., 2012; GOMES ET AL., 2007; MATTOS, 2001; MATTOS, 2004).

De modo sumário, os estudos sobre integralidade compreendem as seguintes dimensões: a) as interações intersubjetivas, a integralidade dos saberes e práticas; b) a integralidade no campo social de trabalho em saúde e no território a partir da integração dos serviços com as famílias, com as comunidades e com as organizações locais; c) a integralidade que se estabelece com os outros níveis de atenção à saúde; e, ainda, d) em ações intersetoriais (MATTOS, 2001; GOMES ET AL., 2007; AYRES, 2009A).

Ainda que esses aspectos apontem para uma gama de políticas e práticas no âmbito da produção social da saúde que requerem um grande conjunto de conexões, tornando, muitas vezes, a integralidade 'tarefa impossível', sua inscrição como objetivo seria uma oportunidade de problematizar o cotidiano das relações entre as equipes de saúde e os usuários e, nesse sentido, 'capaz de mobilizar desejos e vontades' (PASCHE; HENNINGTON, 2006).
Nessa direção, o conceito de potência de ação, elucidado por Espinosa na parte III e IV da Ética, permitirá identificar a afetividade como elemento importante no processo de emancipação do sujeito, o que sugere que, na relação intersubjetiva, os aspectos ligados à necessidade, aos valores éticos, ficam mais salientes. Segundo Espinosa (1973), afetamos e somos afetados configurando nossas potencialidades, as quais dependem de afetos alegres para que juntos possamos transformar a nós e a realidade que nos circunda. Nessa linha de pensamento, os relatos dos profissionais de saúde revelam a importância desses afetos.

Não é novidade a intensidade e a importância do vínculo afetivo que se estabelece no território por meio do trabalho dos profissionais de saúde. Em estudos de revisão sobre a Estratégia Saúde da Família (ESF), verifica-se que, nos últimos anos, houve uma considerável melhoria na relação entre profissionais de saúde e usuários, que se sentem mais acolhidos, apesar de todas as limitações ainda presentes nas práticas de saúde (SILVA: CASOTTI; CHAVES, 2013).

Essas práticas de saúde são produzidas sempre a partir de relações entre atores nos diferentes serviços e territórios. Tal relação de natureza intersubjetiva envolve, necessariamente, uma dimensão dialógica e pressupõe que os profissionais de saúde se relacionem com sujeitos, e não com objetos (MATTOS, 2004). É somente no 'agir com o outro' que se produzem práticas de integralidade. Ou seja, ela 'nunca se dá antes ou fora dessa rede relacional' (GOMES ET AL., 2007).

Dessa perspectiva desdobram-se outras tantas, como as novas formas de produção de conhecimento e de cuidado, que valorizam os saberes científicos, mas, também, os não científicos. Santos (2010) fala de uma 'ecologia de saberes' com o intuito de escapar às amarras de uma modernidade extremamente cientificista e herdeira de um pensamento eurocêntrico, o qual eclipsa outras 
racionalidades. Desse ponto de vista, reforça-se, também, a ideia de valorização da experiência que considera o senso comum, não aquele que reifica e discrimina a partir de crenças, mas aquele que coloca em cheque uma racionalidade científica dogmática, que resulta em desperdício da experiência (SANTOS, 2000).

Essas reflexões deram suporte aos resultados da pesquisa que buscou estudar a potência de ação do Agente Comunitário de Saúde (ACS) em território de alta vulnerabilidade. A imersão no cotidiano de trabalho das equipes de saúde de uma Unidade de Saúde da Família (USF) revelou experiências singulares que contribuíram para uma abordagem contextualizada da atuação do ACS. O sofrimento vivido pelo ACS catalisa a complexidade e as contradições das relações no território, as quais se pode compreender a partir da dialética do processo de inclusão e exclusão social, visto que esse sofrimento é da ordem do ético-político (SAWAIA, 2002) e produzido em contextos de alta vulnerabilidade social, dos quais o ACS faz parte.

Os resultados desta pesquisa indicaram que a prática desse profissional foi desencadeadora de uma compreensão crítica e ampliada do papel social da ESF naquele local (CASTRO-SILVA ET AL., 2014; FRUTUOSO ET AL., 2015). O tráfico de drogas mostra-se como uma força atuante junto às necessidades da população, que, muitas vezes, dita o modo de vida das pessoas (SAPORI; MEDEIROS, 2010). A USF, uma das poucas representações do poder do Estado no território, desenvolve, principalmente, ações pautadas pelo imediatismo, por tarefas ditadas pelos projetos e programas de atenção às doenças mais prevalentes e pelo esforço de superar dificuldades de um sistema pouco resolutivo, reforçador de uma visão biomédica. Tais fatos acabam por restringir ainda mais seu papel de protagonismo social num local onde a participação social é frágil e atravessada por políticas conservadoras e oportunistas (CASTRO-SILVA ET AL., 2014; FRUTUOSO ET AL., 2015).

\section{Percurso metodológico}

Do ponto de vista metodológico, este estudo de caráter qualitativo propiciou avanços na discussão da interface entre a saúde coletiva e as ciências humanas, com ênfase na psicologia social e comunitária e na antropologia aplicadas em um espaço de atenção básica à saúde em território de alta vulnerabilidade social.

Nessa perspectiva, considera-se útil a leitura da realidade a partir da abordagem sócio-histórica e cultural, de base materialista histórico-dialética, na medida em que a historicidade e a crítica são parâmetros de análise dos fenômenos sociais. Isso significa valorizar o caráter da reflexividade, ou seja, o homem pensa a si mesmo e em seu mundo permeado pelo contexto histórico em que vive:

A consciência da historicidade ocorre no interior de uma rede de eventos difundida no tecido societário. Aqueles tempos históricos permitiram aos agentes sociais uma compreensão reflexiva, um novo entendimento de si mesmos. Viram-se ante o espelho de seu próprio modo de vida, de suas inquietações. (MAIA, 2013, P. 71).

A categoria de historicidade possibilita a desnaturalização de processos de saúde-doença e cuidado, pois suscita a apreensão das contradições sociais e históricas dos territórios e das comunidades, vividas no cotidiano das equipes de saúde. Dessa forma, corrobora-se Mattos (2004) ao discutir a importância da valorização de algumas experiências que possam contribuir para este debate e a contextualização de tais práticas, como fator relevante para um aprofundamento dos sentidos da integralidade em saúde.

O local do estudo foi a Vila dos Pescadores (VP), região dos manguezais de Cubatão, que teve sua origem nos anos de 1970 e está inserida no âmbito das transformações do espaço urbano ao longo das últimas décadas, onde se revela um quadro típico de exclusão. 
Há de se destacar o grave problema de infraestrutura básica no local, especialmente com relação às palafitas localizadas no Rio Casqueiro, onde os dejetos e o lixo são depositados diretamente na maré, passando ao lado ou sob as moradias. Por se tratar de uma área de ocupação irregular, o governo não se compromete com melhorias na infraestrutura local. De acordo com dados estatísticos e epidemiológicos, a VP é considerada região de alta vulnerabilidade do município de Cubatão.

Indicadores sociais e de saúde do estado de São Paulo colocam a região administrativa da Baixada Santista, composta por nove municípios, incluindo o de Cubatão, entre as regiões de maior vulnerabilidade do estado. Cubatão é o único município não litorâneo da Baixada Santista e possui um perfil econômico predominantemente voltado para a indústria. $\mathrm{O}$ rápido processo de industrialização dos anos de 1950, acompanhado de uma urbanização desordenada, esgarçou os limites dos bairros periféricos da cidade e, atualmente, estende-se pela área continental de forma predatória, sobre importantes manguezais, ampliando os danos ambientais.

Tomando como ilustração o Índice Paulista da Primeira Infância, que reflete a capacidade do município de promover o desenvolvimento infantil por meio do acesso aos serviços de saúde e educação voltados às crianças menores de seis anos, sete dos nove municípios da região (incluindo Cubatão) encontram-se nos grupos com índice muito baixo e baixo, para o ano de 2014, correspondendo ao extremo de maior vulnerabilidade (SEADE, 2015). Já o Índice Paulista de Responsabilidade Social, a partir de dados de 2012, aponta que Cubatão, com relação às dimensões sociais, apresenta níveis de longevidade e de escolaridade abaixo da média do estado (SÃO PAULO, 2012).

As etapas da pesquisa realizada entre os anos de 2011 e 2013 foram: a) reconhecimento do território para compreender a organização do sistema de saúde, a organização social e comunitária e a organização da USF; b) realização de observações participantes das práticas dos ACS, registradas em diários de campo; e c) realização de entrevistas semiestruturadas, gravadas e transcritas, com oito ACS, quatro gestores do serviço público de saúde de Cubatão, quatro profissionais da USF, a fim de compreender suas trajetórias de vida e seu trabalho. Os critérios de seleção dos sujeitos de pesquisa levaram em consideração o tempo na função maior que um ano, a disponibilidade de participar da pesquisa e a indicação pelos pares.

A sistematização dos dados consistiu da leitura flutuante do material, da qual emergiram as principais categorias empíricas organizadas em quadros descritivo-analíticos. A análise dos dados foi realizada por meio da hermenêutica de profundidade, que propõe a análise de fenômenos culturais, contextualizados sócio-historicamente, e uma metodologia que privilegia os fenômenos culturais e suas formas simbólicas, dentro de contextos estruturados (THOMPSON, 1995).

Todos os procedimentos éticos foram cumpridos conforme orientações do Comitê de Ética em Pesquisa, consubstanciados pelo CAAE: 06454412.3.0000.5505, segundo as recomendações sobre éticas de pesquisa consagradas no Brasil. Os Termos de Consentimento Livre e Esclarecido (TCLE) foram obtidos junto aos participantes.

\section{Resultados e discussão}

Uma das categorias presentes nos discursos de profissionais e gestores evidenciou processos de trabalho em saúde orientados pela integralidade como prática intersubjetiva, temática a ser aprofundada neste artigo e apresentada em duas dimensões: 'integralidade: vínculos e compromisso ético-político'; e 'integralidade: conexões e diálogos inter e intrasetoriais', conforme será visto a seguir. 


\section{Integralidade: vínculos e compromis- so ético-político}

Ainda que muitos profissionais não tenham uma formulação teórica sobre a integralidade, muitos a praticam no seu cotidiano (MATTOS, 2004). Nos depoimentos dos gestores e profissionais de saúde sobre suas práticas profissionais, as diversas dimensões da integralidade são expressas a partir dos desafios e das possibilidades das relações entre recursos e sujeitos. Não é possível pensar em integralidade sem levar em conta essa interação entre sujeitos, profissionais de saúde e usuários e de profissionais entre si sem considerar o contexto de intersubjetividade da macropolítica à microesfera do cuidado (AYRES, 2009A).

A dimensão das interações intersubjetivas está presente nas diversas práticas em saúde da USF. Em algumas situações, pode-se perceber uma atitude mais proativa e colaborativa dos gestores na busca de resoluções de situações a partir de seus próprios recursos locais, o que expressa um afeto potencializador e coletivo:

A gente tinha esta articulação, a gente se reunia independente da nossa chefia, com consentimento e com ciência, mas no sentido de organizar uma rotina de trabalho, e aí eliminar todos os gargalos que existiam e ainda existem. (Gestor).

Embora o gestor reitere, mais adiante, nesse discurso, a 'falta' de infraestrutura do serviço, a relação intersubjetiva revela o potencial de ação dos atores envolvidos, indicando a importância do protagonismo e de estratégias que reforçam a construção coletiva e que ganham forma e expressão no espaço de encontro dos diferentes sujeitos implicados na produção do cuidado. $\mathrm{O}$ debate em torno da integralidade converge, portanto, para um modelo de saúde concebido a partir de tecnologias relacionais, possibilitando dar respostas adequadas às necessidades e demandas. $\mathrm{O}$ vínculo entre a equipe amplia os laços relacionais, desenvolve afetos e potencializa o processo terapêutico (SANTOS; ASSIS, 2006).

Também, os ACS exemplificam ações que valorizam os vínculos intersubjetivos e a dimensão do campo social de trabalho em saúde, uma vez que descrevem em suas práticas relações que estabelecem com as famílias e a comunidade, para além do espaço físico da USF. Nesse caso, a ACS compreende seu papel para além de uma mediação, assumindo um protagonismo solidário na consumação de uma determinada ação do serviço de saúde.

Já cheguei até ir de ambulância para o hospital, porque não tinha parente para acompanhar, e eu me dispus a ir, pedi autorização para sair da Unidade, para acompanhar meu munícipe até o Pronto-Socorro. (ACS).

É possível destacar, das falas de gestores e profissionais, que esses vínculos evidenciam, por um lado, um comprometimento ético-político fundamental para encaminhamentos que buscam concretizar a integralidade. Os profissionais revelam conhecer o funcionamento do sistema e suas conexões e descrevem ações que ilustram resolutividade, reforçando que há exemplos de conhecimento-ação relacionados à integralidade do cuidado. Por outro lado, pode-se perceber uma exacerbação do seu papel de ACS na medida em que assume para si a responsabilidade dessa ação. Nesse sentido, percebe-se a complexidade da dimensão da ética na medida em que está associada ao contexto histórico-político e institucional no qual os profissionais estão inseridos.

Apesar dos ACS serem reconhecidos como sujeitos importantes para a construção da integralidade, que estabelecem diálogos e trocas com os profissionais e exercerem um papel resolutivo, notam-se expressões contraditórias quanto ao efetivo protagonismo desses profissionais na equipe:

Eu estou sempre junto com o agente comunitário. 
Vou lá, sento e converso. O agente faz parte da gente aqui, então, ele é meu braço, como é o braço do médico, da enfermeira, do atendente ali, do pessoal do agendamento de consulta ou do pessoal do agendamento de exames, porque o agente vai, ele capta o problema e vai. (Profissional de saúde).

Também, com relação à comunidade, observa-se que as contradições tornam ainda mais difícil a manutenção de vínculos, pois, algumas vezes, o profissional deve apostar especialmente em mecanismos informais e relações pessoais para garantir o cuidado em situações de precariedade de infraestrutura básica dos serviços de saúde, como no caso da 'falta de pomada':

A gente passa as necessidades para as enfermeiras e para a médica e, muitas vezes, a gente acaba fazendo coisas fora do que a gente tem que fazer. Hoje mesmo fui na casa de uma paciente, e ela estava sem uma pomada. Eu liguei para minha irmã, que trabalha no Pronto-Socorro da zona Noroeste - ela é auxiliar de enfermagem -, e ela vai pegar para mim. A gente acaba se adaptando, faz o nosso serviço, o que é pedido, e acaba tendo que fazer outras coisas, por dois motivos: a gente acaba se compadecendo do paciente e, se a gente só fizer o que está ali no papel, a gente não vai ser bem recebido. E assim a gente acaba criando um grande vínculo com a população. (ACS).

Nessa linha, percebe-se que há outro elemento para o aprofundamento do compromisso ético-político: a solidariedade. O que conduz a aproximar as noções de integralidade e solidariedade é o caráter relacional que atravessa as vivências, oferecendo as oportunidades de criar e recriar sentidos e significados acerca das práticas. A integralidade parece ser construída por esse sentimento solidário, indicando que a afetação gera ações, nesse caso, potência de ação, pois o ACS recorre a um profissional de outro serviço para conseguir a pomada. A integralidade, na perspectiva sócio-histórica, fala de um sujeito que se realiza ou realiza sua humanidade por meio da interação contextualizada com o outro (SAWAIA, 2002). Sem ser afetado, não há ação, não há vínculo e, por fim, não há resolutividade.

A gente às vezes tem medo de resolver essas coisas. Eu arrumei uma vaga na creche para uma criança. Pensei que a mãe dele ficaria ofendida, porque elas não fazem, e, se você for fazer, dependendo de quem for, pode se ofender. (ACS).

Eu já consegui até alimento para uma pessoa que estava precisando. Eu consegui... então, quer dizer, o trabalho do agente comunitário não se resume apenas na saúde da pessoa. (ACS).

A solidariedade é "conexão recíproca ou interdependência" (ABBAGNANO, 2007, P. 918), o que significa também entendê-la a partir da diversidade e da alteridade. No discurso anterior, essa característica é reforçada pela capacidade de se colocar no lugar do outro. No caso do trabalho do ACS, entrar em contato com a história de vida das pessoas significa vivenciar sentimentos ambíguos e intensos, tendo em vista a implicação das determinações sociais da saúde em territórios vulneráveis, inclusive, destacando a importância destas para o exercício efetivo de uma visão integral da pessoa e da comunidade (ALBUQUERQUE; SILVA, 2014).

Na perspectiva da dinâmica institucional, nota-se que os afetos, que poderiam ser potencializadores de transformações na qualidade da assistência, ficam encapsulados em subjetividades apartadas do contexto, da vivência cotidiana do trabalho dos ACS. Um exemplo decorrente disso é o sofrimento gerado pela angústia de não conseguir dar um atendimento ao usuário do serviço. No relato de um gestor, é reforçado o papel do ACS quando, a partir da interação com pessoas no território, leva a demanda para o serviço de saúde e também aponta as fragilidades da atenção à saúde: 
Sensibilidade de serem, não porta voz da população, mas de levarem essa demanda até o posto de saúde. E aí elas sofrem muito com isso. 'Você vai marcar o cardiologista para aquela paciente, porque ela não pode esperar mais!'. Elas se colocam no lugar do paciente. E são elas que acabam direcionando, de uma certa forma, a política pública, porque elas mostram para a gente uma demanda, uma situação que a gestão muitas vezes não enxerga, e, a partir disso, você acaba pensando uma política. (Gestor).

Considera-se que tais afetos podem ser transformadores se articulados com a dimensão política ou, dito de outro modo, se houver a politização dos afetos. Isso sugere, inicialmente, e, cabe reforçar, nas perspectivas sócio-histórica e dialética, a concepção de um sujeito que se forma na interação com seu meio social (SILVA; CASOTTI; CHAVES, 2013). Nessa linha, politizar os afetos significa compreender, de uma maneira crítica, que as causas do sofrimento são desencadeadas pelas precárias condições de vida, ou seja, pelas determinações sociais, qualificadas por Sawaia (2002) como sofrimento ético-político.

\section{Integralidade: conexões e diálogos inter e intrasetoriais}

A inter e a intrasetorialidade, entendidas de forma ampla, compreendem a conexão entre setores e, sobretudo, entre sujeitos de setores sociais diversos para enfrentar problemas complexos. Essa perspectiva demanda, no entanto, um significativo esforço, no plano da interação, entre profissionais e usuários, para o estabelecimento de relações horizontais que favoreçam as possibilidades de diálogo, bem como no plano das articulações, entre saberes, setores de atividade e setores sociais.

Alguns discursos apontam a dimensão da articulação intersetorial de forma ampla, a exemplo da afirmação de que a integralidade

é questão dos direitos, porque é necessário integrar os vários setores e equipamentos para a gente poder levar uma saúde de mais qualidade e mais completa para a população. (Gestor).

Os discursos também manifestam o desejo de se articular e revelam os esforços empreendidos, apesar da precariedade e das dificuldades próprias do estabelecimento de políticas públicas integradas em territórios marcados pela exclusão. Essa integração poderia ser potencialmente maior, porém, limita-se às 'ações pontuais', como, por exemplo, ‘um encaminhamento' ou o uso de espaços cedidos para reuniões:

A gente tenta oferecer um serviço [...] a gente não teve um trabalho junto com as ONGs, o Exército de Salvação e o Grupo de Apoio à Criança, com a Pastoral da Criança. Já existia um direcionamento das crianças que estavam subnutridas para a Pastoral da Criança, mas não era uma coisa, assim, como uma política implementada, era uma ação pontual. Aquela criança precisa, e a gente tem contato com a equipe da Pastoral, e a gente encaminha. A gente utilizava, também, bastante o Centro Comunitário, até porque a gente não tinha sala de reunião. (Gestor).

O que se tem observado é que a fragmentação de setores e práticas é uma realidade cotidiana, assim como a tensão permanente entre movimentos que tendem à interação e à articulação e, contrariamente, ao isolamento e ao distanciamento. Nessa linha, o incremento de articulações com as organizações de base comunitária torna-se essencial para o fortalecimento da participação social, aspecto que, segundo estudos de revisão sobre a ESF, tem se mostrado incipiente (SILVA; CASOTTI; CHAVES, 2013).

A USF, com duas equipes, é o único equipamento público no bairro. As demais organizações, de base comunitária, como a sociedade amigos de bairro, a igreja e uma unidade educacional para crianças do Exército da Salvação, pouco se articulam às ações empreendidas pela USF.

Uma importante líder comunitária nos 
relata a importância da igreja no enfrentamento de situações difíceis vividas em sua família. Segundo seu relato, sua vida foi marcada por tragédias familiares (morte de dois filhos, marido e um filho alcoólatra e uma filha com epilepsia). Não parece ser diferente com a ACS que mora no território e busca na igreja um apoio na criação dos filhos:

Eu sou evangélica. Fiquei uns 15 anos afastada e eu estou retornando porque eu gosto, para instruir meus filhos. Não é para passar tempo, para ocupar o tempo deles, porque é bom ter uma religião, e assim você acaba conhecendo outras pessoas, outro tipo de gente. (ACS).

Particularmente, a igreja exerce um papel importante no território, pois mostra-se muito presente na convivência comunitária entre os moradores da VP e entre os profissionais de saúde, parecendo ocupar um lugar de suporte psicossocial para as pessoas. A relação da igreja com a sociedade é uma questão bastante ampla e complexa e reflete na condução de políticas públicas, que, na sua ausência, são os únicos recursos ofertados às classes mais vulneráveis. A religiosidade no Brasil constitui-se em uma ferramenta para lidar com os sofrimentos cotidianos e pode abrigar a contradição, proporcionando, às vezes, e ao mesmo tempo, libertação e aprisionamento (DALGALARRONDO, 2008).

A falta de articulações, que ocorre no nível intersorial, é também percebida no nível intrasetorial, isto é, entre os níveis de atenção à saúde. Ela aparece como predominante no discurso dos gestores, que pontuam inúmeros aspectos, como a dificuldade, na prática, de comunicação entre os serviços e os profissionais. É certo que essa dificuldade reflete na fragilidade de vínculos estabelecidos entre os serviços de saúde e os usuários, a ponto de impedir qualquer forma de acesso ao sistema, como bem relatou o Gestor:

Nós temos uma grande dificuldade porque os equipamentos não se conversam, embora pareça uma coisa integrada, na prática, não acontece muito. Então, você vê muito paciente pulando de serviço em serviço, isso até a hora em que ele consegue adentrar o sistema. (Gestor).

Mesmo quando as várias dimensões da integralidade parecem já estar em pleno processo de ampliação e requalificação no plano discursivo, o acompanhamento dos usuários na rede de serviços de saúde é um dos grandes desafios a serem enfrentados no município. Nesse caso, observa-se um excesso de tecnicismo e burocratização do atendimento, os quais obstaculizam qualquer projeto terapêutico que vincule o usuário ao serviço. Em consequência, gera desistências e processos de cuidado inconclusos, resultantes de um sofrimento intenso, tanto para profissionais como para usuários:

Então, também, a contrarreferência e a referência ela não é feita corretamente. Já existe uma deficiência no preenchimento do prontuário. $\mathrm{O}$ médico, já na hora de preencher, já coloca: neurologista. Só preenche duas linhas no prontuário da pessoa, põe lá o valor da pressão, não coloca o que a pessoa tinha. (Gestor).

A gente fala integralidade dos serviços de saúde, atender o paciente em todas as suas necessidades, então, quando a gente agenda a consulta de cardiologia, não é só agendar a consulta de cardiologia, é entender o porquê que ele está sendo encaminhado e fazer o tratamento pós. Então, é nesse sentido que a gente fala de integralidade das ações e dos serviços de saúde. (Gestor).

A atenção à saúde mental mostra-se emblemática com relação às fragilidades da integralidade, pois evidencia os impactos da determinação social agravados pela precariedade do sistema. O esforço dos profissionais, relatado na pesquisa, minimiza tais fragilidades, no entanto, estas exigem disposição e empenho para efetivar os encaminhamentos previstos. 
Agora, referente à coordenação, você acaba abrangendo mais o vínculo do Caps (Centro de Apoio Psicossocial) junto ao hospital e aos demais serviços. Você acaba articulando a rede. Hoje, temos um paciente que está no hospital há três meses, porque ele é andarilho, não tem documento... Na sexta-feira, entrei em contato com o Cimpri (Centro de Intervenção ao Migrante, População de Rua e Itinerante) para ver o que a gente pode fazer para devolver esse paciente para o território. Então, você articula a rede com os demais serviços. (Profissional de saúde).

Essas considerações reforçam a ideia de integralidade, vinculada à perspectiva da visão integral dos sujeitos, muito difundida e referenciada aos demais princípios doutrinários do Sistema Único de Saúde (SUS). Afinal,

aprendemos que universalização, equidade e integralidade são mutuamente referentes, cada um reclamando os demais para que se possa compatibilizar pragmatismo com utopia, realismo prático com capacidade de sonhar. (AYRES, 2009B, P. 13).

Reforçam, também, a ideia de sociabilidade e de redes, movidas por desejos e interesses, construídas no tecido social comunitário, nas quais a USF está incluída com profissionais de saúde implicados no enfrentamento de problemas, ainda que em condições consideradas adversas.

\section{Considerações finais}

Após mais de vinte anos desde a implantação, a ESF enfrenta muitos desafios relacionados à reorganização do sistema de saúde e ao enfrentamento dos determinantes sociais da saúde. Tal constatação direciona o olhar para a necessidade de compreensão das consequências da desigualdade social na efetividade das ações de produção social de saúde em locais marcados pela pobreza extrema e pelos fatores associados, como a violência e o tráfico de drogas.
Ressalta-se, portanto, que a contextualização de determinadas experiências marcadas por processos de exclusão social, que indicam o agravamento das condições de vida, exige uma análise referenciada em parâmetros ético-políticos, pois contextualizar ações de saúde integradas e articuladas, valorizando uma sintonia entre necessidades e práticas, implica a superação de obstáculos provindos da exclusão social dos direitos básicos de grande parte da população atendida pela ESF. Assim, reforça-se que o princípio da integralidade seja referenciado a partir desses parâmetros e valorize a experiência dos sujeitos envolvidos nas práticas de saúde e os vínculos intersubjetivos.

Trazer reflexões sobre a integralidade por meio de discursos e práticas, em território marcado pela exclusão social, enseja um grande desafio para profissionais de saúde e outros atores sociais comprometidos com a transformação social, pois revela o esforço de um olhar mais sensível, que implica uma visão totalizante de sujeito.

Poder-se-ia interrogar sobre qual caminho seguir. Não há uma simples e única resposta, visto que as intersubjetividades construídas nos diferentes territórios suscitam respostas singulares e, também, coletivas. Entretanto, pode-se indicar a possibilidade de conexão entre afeto e política, ou de outra forma de politização dos afetos, visto que estes, ao serem construídos socialmente, refletem os hábitos e a visão de mundo. Nessa linha, a visão sócio-histórica serve de parâmetro de análise e interpretação da realidade, dado que busca a vivência dos sujeitos.

Ainda, seria possível vicejar ações coletivas pautadas pela participação social. Na imbricação desta última com a subjetividade, compreende-se que a participação é inerente à natureza humana, e não antagônica a ela, como é vista num contexto regido pelas normas de convivência capitalista (SAWAIA, 2002). Neste sentido, fala-se em vários níveis de conexão e trocas que podem ser produzidos na convivência cotidiana 
entre as pessoas. Conexões que iluminam e qualificam as dimensões macro e micropolíticas do sistema de saúde e da prática da integralidade.

\section{Referências}

ABBAGNANO, N. Dicionário de Filosofia. 5. ed. São Paulo: Martins Fontes, 2007.

ALBUQUERQUE, G. S. C.; SILVA, M. J. S. Sobre a saúde, os determinantes da saúde e a determinação social da saúde. Saúde em Debate, Rio de Janeiro, v. 38, n. 103, p. 953-965, 2014. Disponível em: <http://www.scielo. br/pdf/sdeb/v38n103/0103-1104-sdeb-38-103-0953. pdf>. Acesso em: 23 nov. 2016.

AYRES, J. R. C. M. Organização das ações de atenção à saúde: modelos e práticas. Saúde e Sociedade, São Paulo, v. 18, supl. 2, p. 11-23, abr./jun. 2009a. Disponível em: <http://www.scielo.br/scielo.php?pid=S0104$-12902009000600003 \&$ script $=$ sci_abstract\&tlng=pt $>$. Acesso em: 23 nov. 2016.

Prefácio à $8^{\mathrm{a}}$ edição. In: PINHEIRO, R.;

MATTOS, R. A. Os sentidos da integralidade na atenção e no cuidado à saúde. 8. ed. Rio de Janeiro: Uerj; IMS; Abrasco, 2009b. p. 11-14.

AYRES, J. R. C. M. et al. Caminhos da integralidade: adolescentes e jovens na Atenção Primária à Saúde. Interface, Botucatu, v. 16, n. 40, p. 67-82, jan./mar. 2012. Disponível em: <http://www. scielo.br/scielo.php?script=sci_arttext\&pid $=$ S1414-32832012000100006>. Acesso em: 23 nov. 2016.

CASTRO-SILVA, C. R. et al. Participação social e a potência do agente comunitário de

\section{Colaboradores}

Todos os autores participaram de todas as etapas deste estudo. saúde. Psicologia e Sociedade, Belo Horizonte, v. 26, n. 2, p. 113-123, 2014. Disponível em: <http:// www.scielo.br/scielo.php?script=sci_arttext\&pid $=$ S0102-71822014000600012 >. Acesso em: 23 nov. 2016.

DALGALARRONDO, P. Religião, psicopatologia e saúde mental. Porto Alegre: Artmed, 2008.

ESPINOSA, B. Ética. In: ESPINOSA, B. Os pensadores. São Paulo: Abril, 1973.

FRUTUOSO, M. F. P. et al. Gestão local de saúde em território de vulnerabilidade: motivações e racionalidades. Saúde em Debate, Rio de Janeiro, v. 39, n. 105, p. 337-349, jun. 2015. Disponível em: <http://www.scielo. br/pdf/sdeb/v39n105/0103-1104-sdeb-39-105-00337. pdf>. Acesso em: 23 nov. 2016.

FUNDAÇÃO SISTEMA ESTADUAL DE ANÁLISE DE DADOS (SEADE). O mapeamento da atenção à primeira infância no estado. 2015. Disponível em: <http:// www.ippi.seade.gov.br/wordpress/wp-content/uploads/2015/09/mapeamento.pdf>. Acesso em: 21 jan. 2016.

GOMES, P. S. et al. Integralidade como princípio ético e formativo: um ensaio sobre os valores éticos para estudos sobre trabalho em equipe na saúde. In: PINHEIRO, R. et al. Trabalho em equipe sob o eixo da integralidade: valores, saberes e práticas. Rio de Janeiro: IMS, 2007. p. 19-36 
MAIA, C. A. História das ciências: uma história de historiadores ausentes. Rio de Janeiro: Uerj; Faperj, 2013.

MATTOS, R. A. A integralidade na prática (ou sobre a prática da integralidade). Cadernos de Saúde Pública, Rio de Janeiro, v. 20, n. 5, p. 1411-6, out. 2004. Disponível em: $<$ http://www.scielo.br/pdf/csp/ v20n5/37.pdf>. Acesso em: 23 nov. 2016.

Os sentidos da integralidade: algumas reflexões acerca de valores que merecem ser defendidos. In: PINHEIRO, R.; MATTOS, R. A. (Org.). Os sentidos da integralidade na atenção e no cuidado à saúde. Rio de Janeiro: Uerj; Abrasco, 2001, p. 39-64.

PASCHE, D. F.; HENNINGTON, E. A. Promoção da saúde e o Sistema Único de Saúde. In: CASTRO, A.; MALO, M. SUS: ressignificando a promoção da saúde. São Paulo: Hucitec; Opas, 2006. p. 19-40.

SANTOS, A. M.; ASSIS, M. M. A. Da fragmentação à integralidade: construindo e (des) construindo a prática de saúde bucal no Programa de Saúde da Família (PSF) de Alagoinhas, B.A. Ciência \&t Saúde Coletiva, Rio de Janeiro, v. 11, n. 1, p. 53-61, jan./mar. 2006. Disponível em: <http://www.scielo.br/pdf/csc/v1lnl/29448.pdf>. Acesso em: 23 nov. 2016.

SANTOS, B. S. A crítica da razão indolente: contra o desperdício da experiência. São Paulo: Cortez, 2000. Um discurso sobre as ciências. 7. ed. São Paulo: Cortez, 2010.
SÃO PAULO (ESTADO). Assembléia Legislativa. Índice Paulista de Responsabilidade Social - Cubatão. 2012. Disponível em: <http:// http://indices-ilp.al.sp.gov.br/ view/pdf/iprs/mun3513504.pdf >. Acesso em: 21 jan. 2016.

SAPORI, L. F.; MEDEIROS, R. (Org.). Crack: um desafio social. Belo Horizonte: PUC-Minas, 2010.

SAWAIA, B. O sofrimento ético-político como categoria de análise da dialética exclusão/inclusão. In: SAWAIA, B. As artimanhas da exclusão: uma análise ético-psicossocial. 4. ed. São Paulo: Vozes, 2002.

SILVA, L. A.; CASOTTI, C. A.; CHAVES, S. C. L. A produção científica brasileira sobre a Estratégia de Saúde da Família e a mudança no modelo de atenção. Ciência \&t Saúde Coletiva, Rio de Janeiro, v. 18, n. 10, p. 221-232, jan. 2013. Disponível em: <http:// www.scielo.br/scielo.php?script=sci_arttext\&pid $=$ S1413-81232013000100023>. Acesso em: 23 nov. 2016.

THOMPSON, J. B. Ideologia e cultura moderna. Petrópolis: Vozes, 1995.

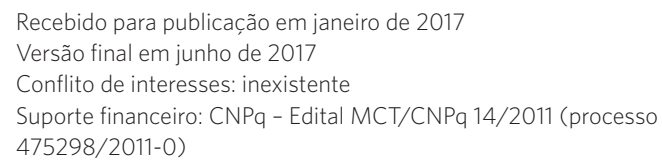

